\title{
THE PREVALENCE OF THE PALMARIS LONGUS MUSCLE'S AGENESIS IN HUNGARIAN STUDENTS
}

\author{
NORBERT BARKATS
}

Ferenc Rakoczi II Transcarpathian Hungarian Institute, Faculty of Sciences, Ukraine

\begin{abstract}
The Palmaris longus muscle (PLM) is a slender, fusiform muscle which lies on the flexor surface of the forearm. Its agenesis is considered the most frequent anatomic variation in the muscular system of the human body. The PLM has little functional use to the human upper limb. It is evidenced by former epidemiological studies that the agenesis of the PLM has a strong racial and ethnic variability. The purpose of this study was to assess the prevalence of the PLM agenesis and its pattern in Hungarian students.

In the present study 385 students of three Hungarian educational institutions were examined. Five standard tests were used to check the presence of a PLM. The PLM was considered to be present if it could be visualized or palpated in at least one of the five tests, and it was considered absent when it could not be palpated or visualized in any of the tests.

The overall rate of the Palmaris longus muscle agenesis was $32.2 \%$. The bilateral agenesis was $18.7 \%$, while the unilateral $13.5 \%$. The agenesis rate on the right and the left hand was $7.27 \%$ and $6.23 \%$ respectively. The prevalence of the PLM agenesis was found to be very similar in the Hungarian populations in Transcarpathia, Ukraine and Slovakia, as well as in Turkey. Our results suggest a genetic relationship between the Turkish and the Hungarian populations.
\end{abstract}

Keywords: musculus palmaris longus; tendon; agenesis; Hungarian students

\section{INTRODUCTION}

The PLM is considered to be a phylogenetically degenerate muscle, its function is no longer necessary for the proper operation of the human hand. 
Probably this is one of the main reasons of its great variability and frequent absence because even without it the human palm can function perfectly. According to the studies done to date, the incidence of the PLM agenesis is gradually increasing. It is suggested that because this muscle is phylogenetically regressive, the PLM will gradually lose its function totally [3]. The PLM is currently one of the most variable muscles in the human body, and its agenesis is the most frequent anatomical variation [4]. The rate of the PLM agenesis varies greatly in different populations. Differences in prevalence of the PLM absence in different populations can be observed in the literature dealing with this topic. It is generally accepted that there is a relation between ethnicity and the frequency of the PLM agenesis [9].

The prevalence of the agenesis of the Palmaris longus muscle among ethnic Hungarians has been studied in Transcarpathia, Ukraine [1], and in Slovakia [2] but, to date, this has not been studied in similar subjects from Hungary.

The aim of the study was to estimate the prevalence of the agenesis of the PLM in the young Hungarian population. To achieve this, students of three Hungarian educational institutions: Eotvos Lorand University (Central Hungary), the University of West Hungary (Apaczai Csere Janos Faculty, Western Hungary), and Eszterhazy Karoly College (Eastern Hungary) were examined. The examined students of these Hungarian educational institutions were of Hungarian ethnic origin, coming from different parts of Hungary.

\section{Subjects and methods}

385 Hungarian students (183 males and 202 females) of the three Hungarian educational institutions (Eotvos Lorand University, the University of West Hungary, and Eszterhazy Karoly) were studied.

The following five tests were used to confirm or refute the presence of a PLM:

1. The Thompson's: the subject is asked to make a fist, then flex the wrist and finally the thumb is opposed and flexed over the fingers [11],

2. The Shaffer's: the subject is asked to oppose the thumb to the little finger and then flex the wrist [10],

3. The Pushpakumar's: the subject is asked to fully extend the index and the middle finger, the wrist and other fingers are flexed and finally the thumb is fully opposed and flexed [8], 
4. The Mishra's 1: metacarpo-phalangeal joints of all fingers are passively hyperextended by the examiner and the subject is asked to actively flex the wrist [7],

5. The Mishra's 2: the subject is asked to abduct the thumb against resistance with the wrist in the slight palmar flexion [7].

For increased accuracy, palpation was performed in every case. This was necessary because of factors (most frequently obesity) which made it impossible to visualize the PML during all the tests, even though it was present. Many cases were observed where the PLM was absent, but the tendons of Flexor carpi radialis or of flexor digitorum superficialis were displayed in a way that could easily be confused with the tendon of the PLM where it was not for palpation.

The PLM was considered to be present in the cases where it could be visualized or palpated in at least one of the five tests, and it was considered absent when it could not be palpated or visualized in any of the tests.

\section{RESULTS}

The PLM was absent in 124 students (32.2\% of all the examined subjects); unilaterally in 52 subjects (13.5\%); bilateral absence was found in 72 subjects (18.7\%; Figure. 1).

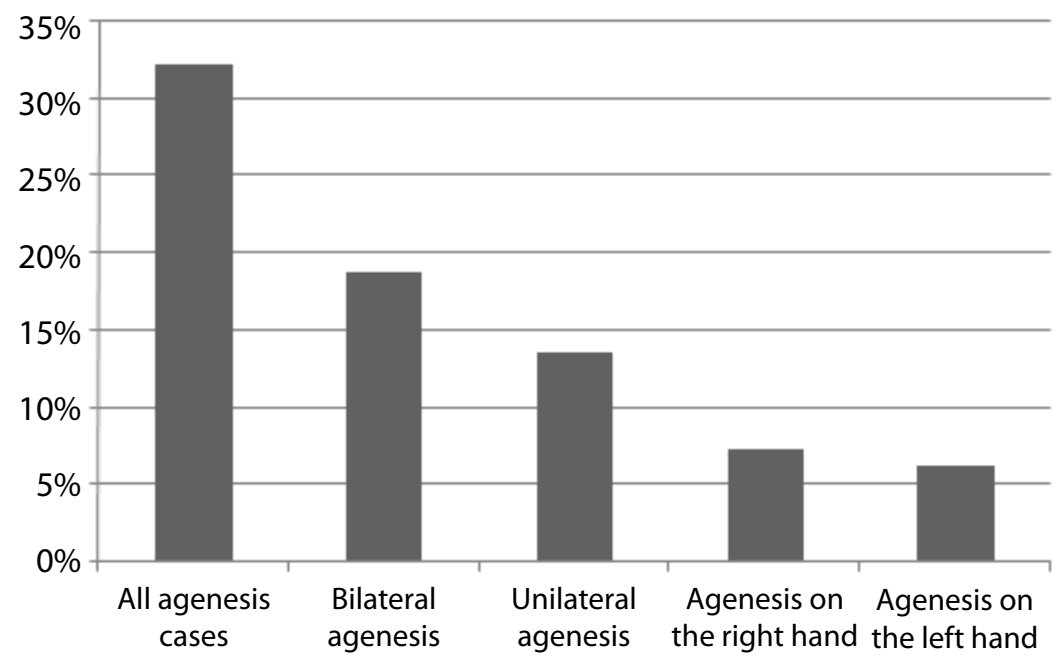

Figure 1. The frequency of the PLM agenesis types in the examined sample 
The PLM was absent unilaterally in 52 subjects (13.5\% of the entire group). This subgroup was made up of 27 female students (7.0\% of the entire group, $13.4 \%$ of all the females), and 25 males (6.5\% of the entire group, $13.7 \%$ of all the males).

In 28 cases ( $7.3 \%$ of all the examined subjects) it was absent in the right hand. This subgroup was made up of 14 females (3.6\% of the entire group, $6.9 \%$ of all the females), and 14 males (3.6\% of the entire group, $7.6 \%$ of all the male students).

In 24 cases (6.2\% of all the examined subjects) the PML was absent in the left hand. This subgroup comprised 13 women (3.4\% of all the subjects, $6.4 \%$ of all the females) and 11 men (2.9\% of all the subjects, $6.0 \%$ of all the males).

Bilateral absence was found in 72 subjects ( $18.7 \%$ of all the subjects). This subgroup was made up of 39 females ( $10.1 \%$ of all the subjects, $19.3 \%$ of all the females) and 33 males ( $8.6 \%$ of all the subjects, $18.0 \%$ of all the male students; Figure. 2).

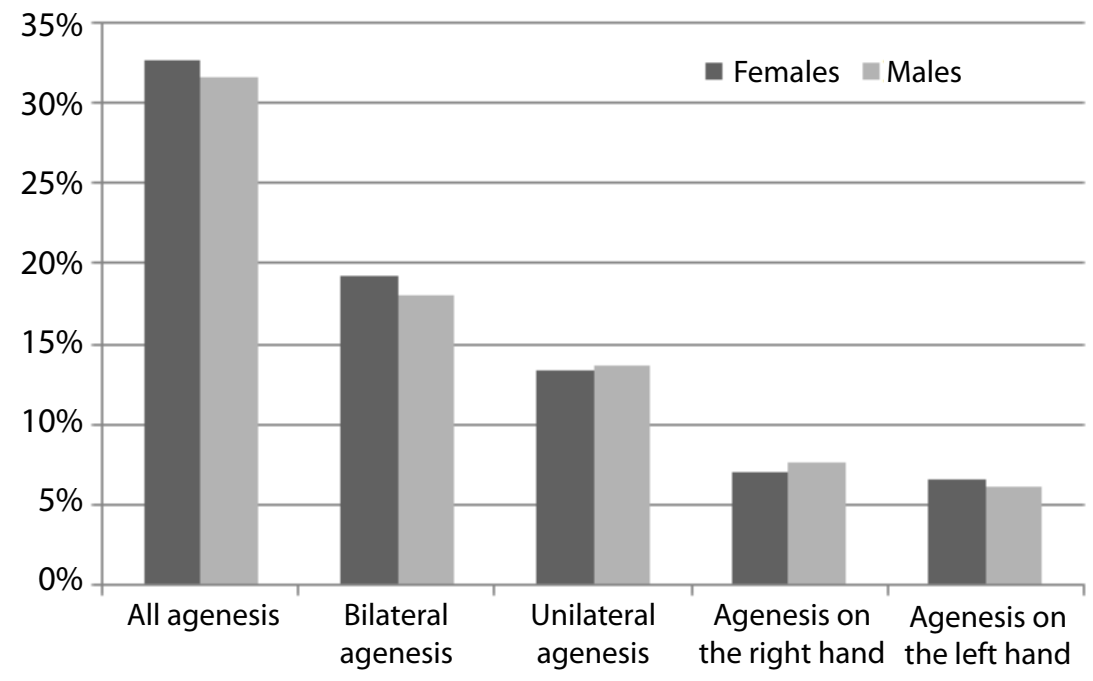

Figure 2. The sexual dimorphism in the prevalence of the PLM agenesis types in the examined sample 


\section{DISCUSSION}

The distribution of the agenesis rate in the sample according to the uni- or bilateral absence, and the agenesis on the left or the right hand among the Hungarian students of Selye János University shows that the bilateral agenesis is higher than the agenesis on the right and the left hand together. $58.1 \%$ of all the agenesis cases is bilateral and only $41.9 \%$ is unilateral. It is unusual for bilateral agenesis to be higher than the unilateral in Caucasian populations, but the similar proportion can be observed in Hungarian population in Transcarpathia, Ukraine [1] and Slovakia [2], and also in Turkey [3; 5; 6]. This may suggest genetic relationship between Turkish and Hungarian ethnic groups, and might be a morphological proof of common origin of Turkish and Hungarian ethnic groups.

Most of the surgeons agree that the palmaris longus tendon is the first choice as a donor tendon during many reconstructive and plastic surgery procedures $[12 ; 13]$. This research has shown that $32.2 \%$ of our subjects have an absent PLM in one or both hands, as the bilateral agenesis rate is higher than the unilateral; it is more likely to encounter a patient with agenesis on both hands. The same tendency can be seen in the Hungarian population of Transcarpathia, Ukraine [1] and Slovakia [2]. This means that the surgeons wishing to use the PML tendon for treating patients of Hungarian ethnic origin, that need tendon grafts for injury repair or during reconstructive or plastic surgery, should be prepared to use an alternative method in the patients who have no PML. It may also cause complications in some cases of median nerve blocks (regional anesthesia of the median nerve).

\section{REFERENCES}

1. Barkats N. (2012). Agenesis of Palmaris longus muscle in inhabitans of Dercen village. J Cherkasy Nat Univ. Ser Biol Sci, 2012, 18-24.

2. Barkats N., Nagy M. (2013). Agenesis of palmaris longus muscle in representatives of Hungarian population of Slovakia. Scid Educat New Dimen, 2, 184-187.

3. Ceyhan O., Mavt A. (1997). Distribution of agenesis of Palmaris longus muscle in 12 to 18 years old age groups. Indian J Med Sci 51, 156-160.

4. Gray H., Goss C. M. (1973). Anatomy of the human body. $29^{\text {th }}$ edition. Lea \& Febiger, Philadelphia.

5. Hiz O., Ediz L., Ceylan M. F., Gezici E., Gulcu E., and Erden M. (2011). Prevalence of the absence of palmaris longus muscle assessed by a new examination test 
(Hiz-Ediz Test) in the population residing in the area of Van, Turkey. J Clin Exp Invest, 3, 254-59.

6. Kose O., Adanir O., Cirpar M., Kurklu M., Komurcu M. (2009). The prevalence of absence of the palmaris longus: a study in Turkish population. Arch Orthop Trauma Surg, 129(5), 609-611.

7. Mishra S. (2011). Alternative tests in demonstrating the presence of palmaris longus. Indian J Plast Surg, 34, 12.

8. Pushpakumar S. B., Hanson R. P., Carroll S. (2004). The 'two finger' sign. Clinical examination of palmaris longus (PL) tendon. Br J Plast Surg, 57, 184-185.

9. Reimann A. F., Daseler E. H., Anson B. J., Beaton L. E. (1944). The palmaris longus muscle and tendon. A study of 1600 extremities. Anat Rec, 89(4), 495-505.

10. Schaeffer J. P. (1909). On the variations of the palmaris longus muscle. Anat Rec, 3, 275-278.

11. Thompson J. W., McBatts J., Danforth C.H. (1921). Hereditary and racial variations in the musculus palmaris longus. Am J Phys Anthrop, 4, 205-220.

12. Thompson N. W., Mockford B. J., Cran G. W. (2001). Absence of the palmaris longus muscle: a population study. Ulster Med J, 70(1), 22-24.

13. Troha F., Baibak G. J., Kelleher J. C. (1990). Frequency of the palmaris longus tendon in North American Caucasians. Ann Plast Surg, 25, 477-478.

\section{Address of correspondence:}

Norbert Barkats

Ferenc Rakoczi II Transcarpathian Hungarian Institute

Faculty of Sciences

Vodna str. 19, Munkacs, 89600, Ukraine

Tel.: +380508359091 